\title{
Involvement of mitochondrial swelling in cytochrome $c$ release from mitochondria treated with calcium and Alloxan
}

\author{
Takuya Ichimura, Mika Ito, Kiyoshi Takahashi, Kyohei Oyama and Koichi Sakurai* \\ Division of Biochemistry, Department of Life science, Hokkaido Pharmaceutical University School of Pharmacy, Otaru, Japan; \\ ks51@,hokuyakudai.ac.jp
}

Received 29 October 2010; revised 18 November 2010; accepted 25 November 2010.

\begin{abstract}
An early event in the induction of apoptosis is cytochrome $c$ (Cyt c) release from mitochondria. We investigated the involvement of mitochondrial permeability transition (MPT) and mitochondrial swelling in Cyt $c$ release from mitochondria treated with alloxan and/or calcium $\left(\mathrm{Ca}^{2+}\right)$. When mitochondria were treated with a high concentration of $\mathrm{Ca}^{2+}$ alone or $\mathrm{Ca}^{2+}$ with alloxan (alloxan- $\mathrm{Ca}^{2+}$ ), the MPT was accompanied by mitochondrial swelling and the release of Cyt $c$. Cyclosporin A prevented the induction of MPT but only slightly decreased the release of Cyt $c$. High molecular weight polyethylene glycol almost completely inhibited MPT-dependent osmotic mitochondrial swelling and Cyt $c$ release. However, MPT-independent mitochondrial swelling and Cyt $c$ release induced by exogenous $\mathrm{K}^{+}$were inhibited by the high molecular weight polyethylene glycol. Ruthenium red strongly decreased the amount of Cyt $c$ released. These results suggest that mitochondrial swelling but not MPT is necessary for Cyt $c$ release induced by $\mathrm{Ca}^{2+}$ alone or alloxan and $\mathrm{Ca}^{2+}$.
\end{abstract}

Keywords: Mitochondrial Swelling; Cytochrome $C$ Release; Calcium; Alloxan; Mitochondrial

Permeability Transition

\section{INTRODUCTION}

Mitochondria have a central role in energy metabolism and $\mathrm{Ca}^{2+}$ homeostasis in cells [1-3]. The release of mitochondrial proteins, such as cytochrome $c$ (Cyt $c)$, Smac/DIABLO, and apoptosis inducing factor (AIF), into the cytosol is likely involved in the early events in cell death $[4,5]$. Several triggers of mitochondrial permeability transition (MPT) result in apoptotic cell death
[6-8]. From these findings, it is proposed that the MPT is involved in Cyt $c$ release from mitochondria and apoptosis $[9,10]$. MPT is associated with an increase in the permeability of the mitochondrial inner membrane, allowing the transmission of a solute with a molecular mass of up to approximately $1.5 \mathrm{k} \mathrm{Da}$. MPT is also associated with mitochondrial swelling, followed by the release of mitochondrial proteins including Cyt $c$ [10]. Cytochrome $c$ with a molecular weight of approximately $12 \mathrm{k} \mathrm{Da}$ is loosely bound to phospholipids of the outer surface of the inner mitochondrial membrane, primarily cardiolipin, and functions to transmit electrons from complex III to complex IV of the electron transport chain in mitochondria [11,12]. There are two distinct processes in the Cyt $c$ release from the intermembrane space of mitochondria into the cytosol. One process is the dissociation of Cyt $c$ from the inner membrane, and the other process is the transfer of the dissociated Cyt $c$ through the outer membrane.

Several mechanisms for the release of Cyt $c$ from mitochondria have been proposed. Petrosillo et al. demonstrated that Cyt $c$ is dissociated from the inner mitochondrial membrane response to cardiolipin peroxidation by reactive oxygen species (ROS) prior to the release into the cytosol [12]. Several researchers have proposed that the release of Cyt $c$ occurs due to the rupture of the mitochondrial outer membrane [10,13-17]. Apoptotic Bcl-2 family proteins, such as Bax and tBid, cause Cyt $c$ release from mitochondria by an increase in outer membrane permeability [18-21]. The induction of MPT is due to the opening of the permeability transition pore (PTP), which consists of the voltage-dependent anion channel (VDAC), adenine nucleotide translocator (ANT), cyclophilin D (CyD), and other proteins, such as hexokinase [10]. Because the physiological function of the PTP is to allow high molecular weight substances to pass through the mitochondrial outer membrane, whereas low molecular weight materials such as water, 
oxygen, and carbon dioxide [9] can pass freely through the mitochondrial inner membrane, it has been suggested that PTP has a primary role in the matter transport into mitochondria.

Mitochondria are one of the $\mathrm{Ca}^{2+}$ store sites in cells and contribute to the maintenance of $\mathrm{Ca}^{2+}$ density in the cytoplasm [3]. Excessive $\mathrm{Ca}^{2+}$ accumulation in cells induces MPT $[1,22,23]$. We have previously demonstrated that the diabetogenic compound, alloxan, causes MPT in the presence of $\mathrm{Ca}^{2+}$. Quinone compounds that have a similar structure to alloxan induce MPT in the presence of $\mathrm{Ca}^{2+}$ [8,24-26]. Mangiferin quinoid compounds triggers MPT via interaction with mitochondrial protein thiol groups [27]. The MPT was inhibited by several chemicals, such as inhibitors of the cyclophilin family, mitochondrial $\mathrm{Ca}^{2+}$ uniporter and mitochondrial respiratory chain [28-30], suggesting that the release of Cyt $c$ is induced through several different pathways. However, the mechanism by which Cyt $c$ is released from mitochondria treated with $\mathrm{Ca}^{2+}$ remains largely unknown.

The present study demonstrates the involvements of MPT and mitochondrial swelling in Cyt $c$ release from mitochondria treated with various concentrations of $\mathrm{Ca}^{2+}$ alone or $\mathrm{Ca}^{2+}$ with alloxan (alloxan-Ca ${ }^{2+}$ ). The MPT inhibitors significantly inhibited the MPT induced by $\mathrm{Ca}^{2+}$ alone or alloxan- $\mathrm{Ca}^{2+}$ but did not inhibit Cyt $c$ release. High-molecular weight polyethylene glycol (PEG) almost completely inhibited MPT-dependent osmotic mitochondrial swelling and Cyt $c$ release caused by the large amplitude MPT induced by $\mathrm{K}^{+}$or other inducers. These results suggest that mitochondrial swelling but not MPT relates to Cyt $c$ release from mitochondria treated with alloxan- $\mathrm{Ca}^{2+}$ or high concentrations of $\mathrm{Ca}^{2+}$ alone.

\section{MATERIALS AND METHODS}

\subsection{Materials}

Cyt $c$ (from horse heart), rotenone, ethyleneglycolbis-( $\beta$-aminoethyl ether)-N,N,N',N'-tetraacetic acid (EGTA), stigmatellin (STG), and carbonyl cyanide $m$-chlorophenylhydrazone (CCCP) were purchased from Sigma Chemical Co. (St. Louis, MO). Calcium chloride $(\mathrm{CaCl} 2)$, sodium succinate, potassium chloride $(\mathrm{KCl})$, potassium cyanide $(\mathrm{KCN})$, alloxan, cyclosporin A (CsA), and PEG 4000 (molecular weight of $3 \mathrm{kDa}$ ) were from Wako Pure Chemical Industries Ltd. (Osaka, Japan). Ruthenium red (RuR) was from Kanto Chemical Co. (Tokyo, Japan). The polyclonal anti-Cyt $c$ antibody and the goat antirabbit IgG HRP were from Santa Cruz Biotechnology Inc. (Santa Cruz, CA). The ECL plus Western blotting detection system was from GE Healthcare UK Ltd. (Buckinghamshire, England). The BCA protein assay kit was from Pierce Biotechnology Inc. (Rockford, IL). The other chemicals used in this study were of analytical grade from commercial suppliers.

\subsection{Preparation of Rat Liver Mitochondria}

Male Wistar rats that were approximately $200 \mathrm{~g}$ were used for the experiments after an overnight fast. Mitochondria were isolated in Chelex-100 treated medium containing $0.25 \mathrm{M}$ sucrose, $10 \mathrm{mM}$ Tris- $\mathrm{HCl}(\mathrm{pH} 7.4)$ and $1 \mathrm{mM}$ EGTA by differential centrifugation of liver homogenates as previously described [31]. Mitochondrial protein concentrations were determined by a BCA protein assay kit (Pierce, USA) according to the manufacturer's instruction with bovine serum albumin used as a standard. All rats were treated in accordance with the guiding principles for care and use of experimental animals in Hokkaido Pharmaceutical University School of Pharmacy.

\subsection{Measurement of Mitochondrial Swelling}

Mitochondria (1 $\mathrm{mg}$ of protein $/ \mathrm{ml}$ ) were equilibrated in Chelex-100 treated medium consisting of $10 \mathrm{mM}$ Tris- $\mathrm{HCl}$ (pH 7.4), $0.25 \mathrm{M}$ sucrose and $0.1 \mathrm{M}$ rotenone for $5 \mathrm{~min}$ at $37^{\circ} \mathrm{C}$. After mitochondria were energized by the addition of $5 \mathrm{mM}$ succinate to the mitochondrial suspension for $5 \mathrm{~min}$, mitochondrial swelling was then initiated by adding various MPT inducers $\left(\mathrm{Ca}^{2+}\right.$ and alloxan- $\mathrm{Ca}^{2+}$ ) for $10 \mathrm{~min}$. Mitochondrial swelling induced by $\mathrm{K}^{+}$was initiated by the addition of $80 \mathrm{mM} \mathrm{KCl}$ to mitochondria suspended in Chelex-100 treated medium containing $0.25 \mathrm{M}$ sucrose, $10 \mathrm{mM}$ Tris- $\mathrm{HCl}$ (pH 7.4) and $1 \mathrm{mM}$ EGTA. Mitochondrial swelling was measured by recording the decrease in absorbance at $540 \mathrm{~nm}$ with a spectrophotometer (Hitachi U-2,000, Japan).

\subsection{Release of Cyt $C$}

Released Cyt $c$ was detected by Western blot analysis. After the mitochondrial suspension was treated with various compounds, the suspension was centrifuged at $10,000 \times g$ for $30 \mathrm{~min}$ at $4^{\circ} \mathrm{C}$. The collected supernatant was mixed with loading buffer, boiled for $5 \mathrm{~min}$ and subjected to $15 \%$ SDS-polyacrylamide gel (Atto, Japan) for $40 \mathrm{~min}$ at $200 \mathrm{~V}$ followed by electroblotting to nitrocellulose membranes for $1.5 \mathrm{~h}$ at $2 \mathrm{~mA} / \mathrm{cm}^{2}$. Membranes were blocked for $1 \mathrm{~h}$ with $5 \%$ skim milk in TBS-T at room temperature, rinsed and subsequently probed with a polyclonal anti-Cyt $c$ antibody (1:1,000 dilution) for 1 $\mathrm{h}$ at room temperature. The membranes were rinsed and incubated with a horseradish peroxidase-labeled antirabbit antibody (1:20,000 dilution) for $1 \mathrm{~h}$ at room temperature. After incubation with the secondary antibody, the membranes were rinsed, and the Cyt $c$ blots were visualized by enhanced chemiluminescence using the 
ECL plus western blotting detection system (GE Healthcare, UK). Individual band densities were integrated using the Luminous Imager Software (Aisin cosmos, Japan).

\subsection{Statistical Analysis}

Data were expressed as means \pm standard deviations (S.D.) and were statistically analyzed by either Student's $t$ test (in the case of equal variances between two groups) or Welch's $t$ test (in the case of unequal variances between two groups) after the $F$ test. Data with $P<0.05$ were considered statistically significant.

\section{RESULTS}

\subsection{MPT and Cyt $C$ Release Induced by $\mathrm{Ca}^{2+}$ or Alloxan- $\mathrm{Ca}^{2+}$}

Initially, we studied the relationship between the induction of MPT and the release of Cyt $c$ from rat liver mitochondria treated with several concentrations of $\mathrm{Ca}^{2+}$ (25 M-200 M). As shown in Figure 1(a), after the addition of $50 \mathrm{M} \mathrm{Ca}^{2+}$ to the mitochondrial suspension, the absorbance at $540 \mathrm{~nm}$ decreased by approximately 0.3 for $10 \mathrm{~min}$, indicating the induction of small amplitude MPT. After the addition of $200 \mathrm{M} \mathrm{Ca}^{2+}$, the absorbance rapidly decreased during the first $2 \mathrm{~min}$ and then decreased moderately (A540 nm/10 min was approximately 0.6) indicating the induction of large amplitude MPT. These results suggest that the extent of MPT depends on $\mathrm{Ca}^{2+}$ concentration. We then measured the concentrations of Cyt $c$ released from mitochondria by Western blotting. Addition of $\mathrm{Ca}^{2+}(25 \mathrm{M}-200 \mathrm{M})$ to the mitochondrial suspension clearly induced the release of Cyt $c$ from mitochondria. The concentrations of released Cyt $c$ increased with increasing $\mathrm{Ca}^{2+}$ concentrations but reached a plateau at $\mathrm{Ca}^{2+}$ concentrations of $100 \mathrm{M}$ or more. Moreover, we studied the relationship between MPT and Cyt $c$ release induced by alloxan together with $20 \mathrm{M} \mathrm{Ca}^{2+}$ (alloxan- $\mathrm{Ca}^{2+}$ ). As shown in Figure 1(b), addition of alloxan- $\mathrm{Ca}^{2+}$ to the mitochondrial suspension caused a rapid decrease in absorbance at $540 \mathrm{~nm}$ for approximately $4 \mathrm{~min}$ and, subsequently, a moderate decrease in absorbance ( A540 nm/10 min was approximately 1) Furthermore, the addition of alloxan-Ca ${ }^{2+}$ initiated the Cyt $c$ release from mitochondria (Figure 1(b)). Fluorescence intensity of the bands was correlated with the increase in concentrations of authentic Cyt $c$ (1-100 pmol) in image of Western blotting (Figure 1(c)), and the coefficient of determination $(\mathrm{R})$ between the concentrations of Cyt $c$ and the band intensities was 0.99 . These results indicate that both $\mathrm{Ca}^{2+}$ alone and alloxan- $\mathrm{Ca}^{2+}$ cause the induction of MPT and the release of Cyt $c$ from mitochondria. To elucidate the relationship between MPT and Cyt $c$ release, we studied the effect of CsA, an

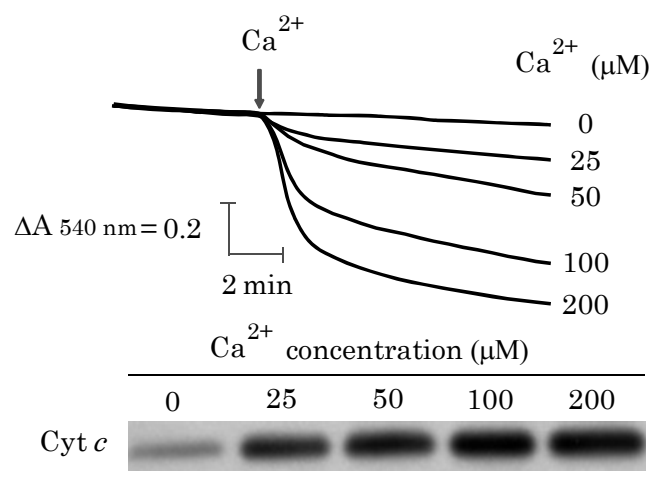

(a)

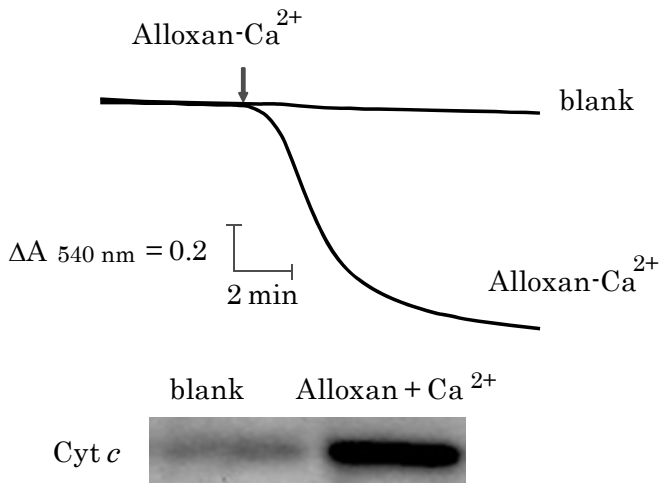

(b)

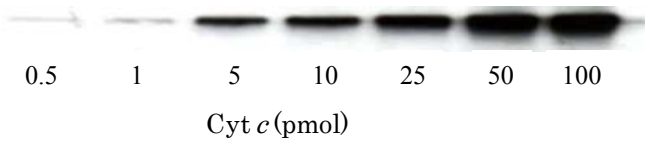

(c)

Mitochondria were incubated in a medium at a concentration of 1 $\mathrm{mg}$ protein $/ \mathrm{ml}$. The incubation medium consisted of $0.25 \mathrm{M}$ sucrose, $0.1 \mathrm{M}$ rotenone, and $10 \mathrm{mM}$ Tris- $\mathrm{HCl}(\mathrm{pH} 7.4)$. MPT was induced by (a) $25 \mathrm{M}-200 \mathrm{M} \mathrm{Ca}^{2+}$ or (b) $1 \mathrm{mM}$ alloxan and $20 \mathrm{M} \mathrm{Ca}^{2+}$ (alloxan- $\mathrm{Ca}^{2+}$ ) in the presence of $5 \mathrm{mM}$ succinate. In blank neither $\mathrm{Ca}^{2+}$ nor alloxan- $\mathrm{Ca}^{2+}$ was included in the medium. Typical traces from three independent experiments are shown. Cyt $c$ was detected by Western blotting. Similar results were obtained in two additional independent experiments; (c) Several concentrations (0-100 pmol) of Cyt $c$ were measured by Western blotting. Typical results of one experiment are shown, and similar results were obtained three different preparations.

Figure 1. Induction of MPT and release of Cyt $c$.

inhibitor of classical MPT, on MPT and Cyt $c$ release. As shown in Figure 2(a), CsA prevented approximately $68 \%$ of total MPT and approximately $26 \%$ of total Cyt c release from mitochondria in the presence of $50 \mathrm{M} \mathrm{Ca}^{2+}$ (Figure 2(a)). However, in high concentrations of $\mathrm{Ca}^{2+}$ (200 M), CsA led to a decrease in total MPT by approximately $82 \%$ but did not significantly affect Cyt $c$ release (Figure 2(b)). Together, these data suggest that Cyt $c$ release from mitochondria is not necessarily related to MPT. 


\subsection{Effects of Inhibitors of Mitochondrial Function on MPT and Cyt $C$ Release}

As shown in Figure 3, we studied the effects of several inhibitors of mitochondrial function including CCCP, $\mathrm{STG}$, and KCN on MPT and Cyt $c$ release from mitochondria treated with $\mathrm{Ca}^{2+}$. Under the condition of $50 \mathrm{M}$ $\mathrm{Ca}^{2+}$, an uncoupler, CCCP, and an inhibitor of b-c1 complex, STG, significantly prevented both MPT and Cyt $c$ release, but $\mathrm{KCN}$ did not affect either one (Figure 3(a)). With $200 \mathrm{M} \mathrm{Ca}^{2+}, \mathrm{CCCP}, \mathrm{KCN}$, and STG signifi-
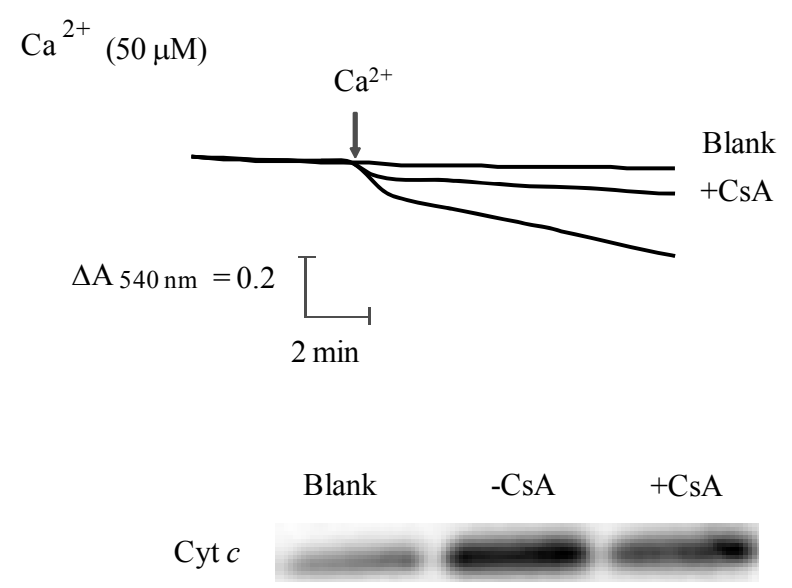

(a)

$\mathrm{Ca}^{2+}(200 \mu \mathrm{M})$
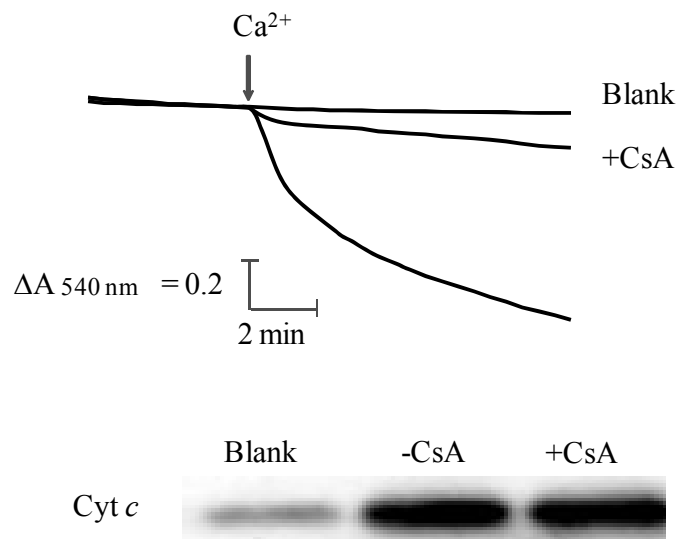

(b)

MPT was induced by (a) $50 \mathrm{M}$ or (b) $200 \mathrm{M} \mathrm{Ca}^{2+}$ in the presence of $5 \mathrm{mM}$ succinate. The incubation medium contained 1 M CsA from the beginning of the experiments. In blank $\mathrm{Ca}^{2+}$ was not included in the medium. Typical traces from three independent experiments are shown. Released Cyt $c$ from mitochondria was detected by Western blotting. Similar results were obtained in two additional independent experiments. The other conditions were the same as previously described in Figure 1.

Figure 2. Effects of CsA on $\mathrm{Ca}^{2+}$-induced MPT and Cyt $c$ release. cantly inhibited MPT, whereas STG, but not CCCP or $\mathrm{KCN}$, strongly decreased Cyt $c$ release (Figure 3(b)). These results suggest that the inhibitors of mitochondrial function have different effects on MPT and Cyt $c$ release caused by low $(50 \mathrm{M})$ or high $(200 \mathrm{M})$ concentrations of $\mathrm{Ca}^{2+}$. We then examined the effects of CsA and the inhibitors of mitochondrial function on MPT and Cyt $c$ release from mitochondria treated with alloxan- $\mathrm{Ca}^{2+}$. In alloxan- $\mathrm{Ca}^{2+}$ conditions, CsA and the inhibitors of mitochondrial function significantly prevented MPT but not Cyt $c$ release (Table 1). These data suggest that processes other than MPT may be involved in Cyt $c$ release.

\subsection{Correlation Between Mitochondrial Swelling and Cyt $C$ Release}

Mitochondrial swelling is caused by the increase in mitochondrial volume, which is determined by a balance

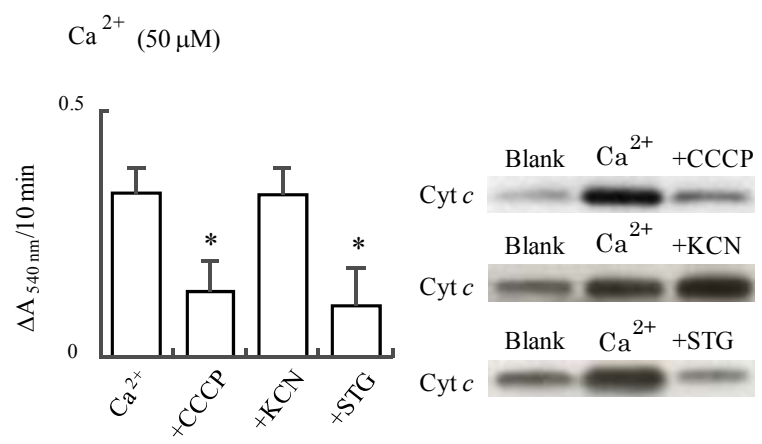

(a)

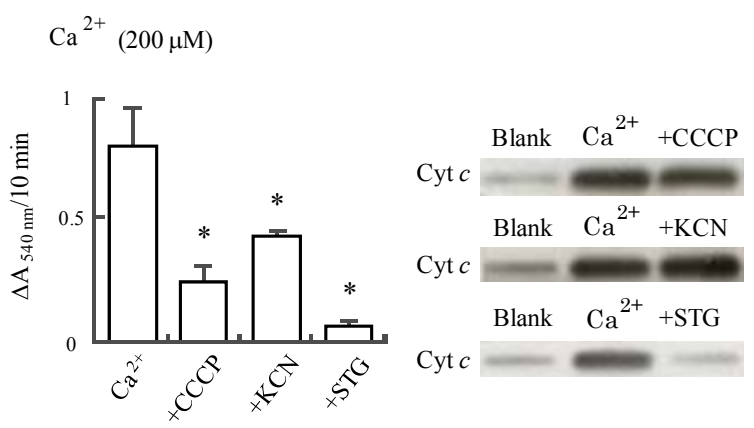

(b)

Inhibitors of mitochondrial function including $0.05 \mathrm{M} \mathrm{CCCP,} 300 \mathrm{M}$ $\mathrm{KCN}$, and $5 \mathrm{M}$ STG were added to the incubation medium from the beginning of the experiments. MPT was induced by (a) $50 \mathrm{M}$ or (b) $200 \mathrm{M} \mathrm{Ca}^{2+}$ in the presence of $5 \mathrm{mM}$ succinate. Value of ordinate refers to the $\mathrm{A}_{540 \mathrm{~nm}}$ for $10 \mathrm{~min}$. Cyt $c$ released was detected by Western blotting. In blank $\mathrm{Ca}^{2+}$ was not included in the medium. Similar results were obtained in two additional independent experiments. Data values are represented as means \pm S.D. of 3 to 11 experiments. * represents $P$ $<0.05$ compared with mitochondria treated with $\mathrm{Ca}^{2+}$ alone. The other conditions were the same as previously described in Figure 1.

Figure 3. Effects of the inhibitors of mitochondrial function on MPT and Cyt $c$ release induced by $\mathrm{Ca}^{2+}$. 
Table 1 .Effect of CsA and mitochondrial function inhibitors on swelling and $\mathrm{Cyt} c$ release induced by alloxan- $\mathrm{Ca}^{2+}$.

\begin{tabular}{ccc}
\hline Conditions & $\Delta \mathrm{A}_{540 \mathrm{~nm}}$ & Cyt $c$ release (a.u.) \\
\hline Alloxan-Ca ${ }^{2+}$ & $1.008 \pm 0.079$ & $2.8 \pm 0.6$ \\
$+\mathrm{CsA}$ & $0.482 \pm 0.155^{*}$ & $2.9 \pm 0.5$ \\
$+\mathrm{CCCP}$ & $0.647 \pm 0.068^{*}$ & $2.2 \pm 0.8$ \\
$+\mathrm{KCN}$ & $0.428 \pm 0.193^{*}$ & $2.9 \pm 0.6$ \\
$+\mathrm{STG}$ & $0.073 \pm 0.031^{*}$ & $2.2 \pm 0.6$ \\
\hline
\end{tabular}

Mitochondrial swelling was induced by $1 \mathrm{mM}$ alloxan and $20 \mathrm{mM} \mathrm{Ca}{ }^{2+}$ (alloxan- $\mathrm{Ca}^{2+}$ ) in the presence of $5 \mathrm{mM}$ succinate. Swelling data refer to the $\mathrm{DA}_{540 \mathrm{~nm}}$ for $10 \mathrm{~min}$. The amount of released Cyt $c$ was analyzed by Western blotting and quantified by densitometry, and is relatively represented as compared to that of mitochondria treated with neither alloxan-Ca ${ }^{2+}$ nor the inhibitors. Data values are represented as a mean \pm S.D. of three to eight experiments. ${ }^{*}$ represents $P<0.05$ when compared to alloxan- $\mathrm{Ca}^{2+}$. The other conditions were the same as previously described in Figure $\mathbf{1}$ and Figure 3.
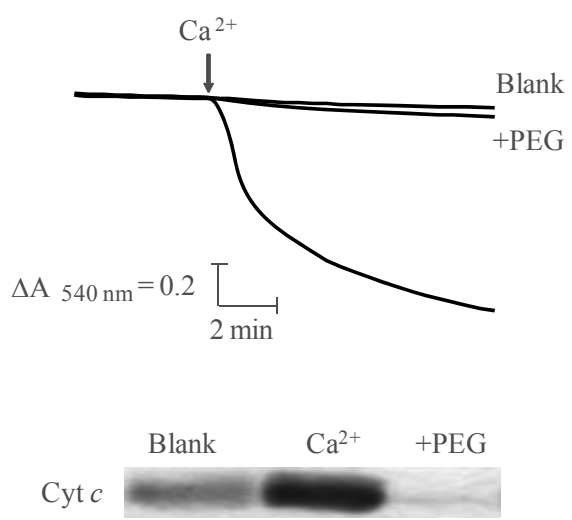

(a)
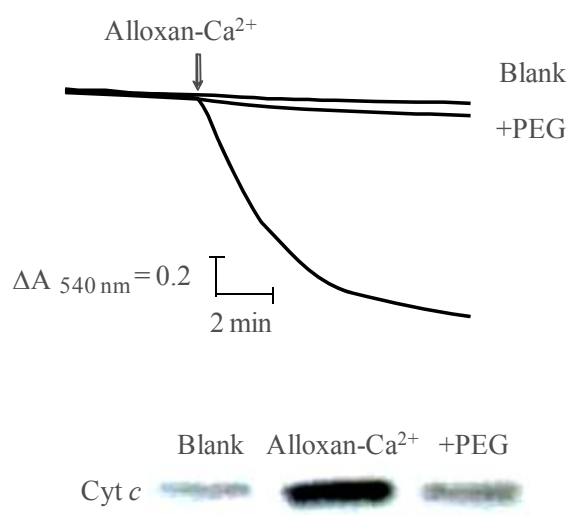

(b)

Mitochondrial swelling was induced by (a) $200 \mathrm{M} \mathrm{Ca}^{2+}$ (b) or $1 \mathrm{mM}$ alloxan and $20 \mathrm{M} \mathrm{Ca}^{2+}$ in the presence of $5 \mathrm{mM}$ succinate. Forty M of PEG 4000 was included in the incubation medium from the beginning of the experiments. Cyt $c$ was detected by Western blotting. In blank neither $\mathrm{Ca}^{2+}$ nor alloxan-Ca ${ }^{2+}$ was included in the medium. Similar results were obtained in two additional independent experiments. The other conditions were the same as previously described in Figure 1.

Figure 4. Effects of PEG on MPT and Cyt $c$ release induced by $\mathrm{Ca}^{2+}$ and alloxan- $\mathrm{Ca}^{2+}$. of osmotic pressure across the inner mitochondrial membrane. To examine the correlation between mitochondrial swelling and Cyt $c$ release from mitochondrial intermembrane space, we examined the effect of PEG on mitochondrial swelling and Cyt $c$ release from mitochondria induced by high concentrations of $\mathrm{Ca}^{2+}$ alone or alloxan- $\mathrm{Ca}^{2+}$. PEG strongly inhibited mitochondrial swelling induced by $\mathrm{Ca}^{2+}$ and completely inhibited Cyt $c$ release from mitochondria (Figure 4(a)). In addition, PEG significantly prevented mitochondrial swelling and Cyt $c$ release from mitochondria treated with alloxan- $\mathrm{Ca}^{2+}$ (Figure 4(b)). These results indicate that mitochondrial swelling associated with MPT is connected with the release of Cyt $c$ from mitochondria.

We next investigated the regulation of Cyt $c$ release from mitochondria with mitochondrial swelling induced by another mechanism that is not mediated by MPT: hypotonic shock triggered by low $\mathrm{K}^{+}$concentrations [32]. As shown in Figure 5, $80 \mathrm{mM} \mathrm{K}^{+}$significantly induced mitochondrial swelling and Cyt $c$ release from mitochondria when compared to a blank which neither $\mathrm{K}^{+}$ nor CsA is included. CsA did not inhibit $\mathrm{K}^{+}$-induced mitochondrial swelling and Cyt $c$ release, indicating that Cyt $c$ release from mitochondria may be due to mitochondrial swelling regardless of functional MPT. CsA
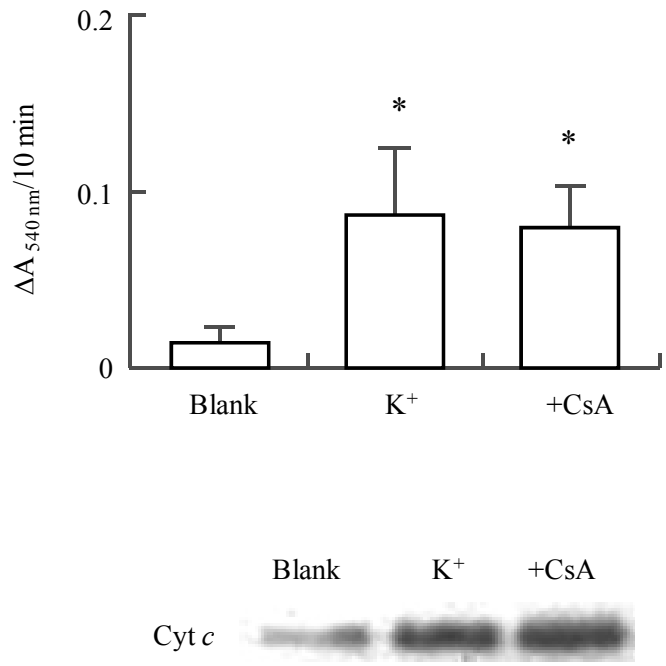

Mitochondria were incubated in a medium at a concentration of $1 \mathrm{mg}$ protein $/ \mathrm{ml}$. The incubation medium consisted of 0.25 $\mathrm{M}$ sucrose, $0.1 \mathrm{M}$ rotenone, $5 \mathrm{mM}$ succinate, $0.1 \mathrm{mM}$ EGTA, and $10 \mathrm{mM}$ Tris- $\mathrm{HCl}(\mathrm{pH}$ 7.4). Mitochondrial swelling was induced by $80 \mathrm{mM} \mathrm{K}^{+}$. The incubation medium contained $1 \mathrm{M}$ CsA from the beginning of the experiments. Value of ordinate refers to the $\mathrm{A}_{540 \mathrm{~nm}}$ for $10 \mathrm{~min}$. Data values are represented as means \pm S.D. of three separate experiments. Cyt $c$ was detected by Western blotting. In blank neither $\mathrm{Ca}^{2+}$ nor $\mathrm{K}^{+}$was included in the medium. Similar results were obtained in two additional independent experiments. * represents $P<0.05$ when compared to the blank.

Figure 5. $\mathrm{K}^{+}$-induced mitochondrial swelling and Cyt $c$ release. 
alone did not cause MPT or Cyt $c$ release from mitochondria (data not shown). These results suggest that mitochondrial swelling may act as a major regulator of Cyt $c$ release from mitochondria treated with $\mathrm{K}^{+}$.

\subsection{VDAC Opening May Be Involved in Cyt C Release}

To investigate the involvement of the passage process through the mitochondrial outer membrane in Cyt $c$ release, we studied the effect of RuR that inhibits both the mitochondrial $\mathrm{Ca}^{2+}$ uniporter and the VDAC opening. As shown in Figure 6(a), RuR significantly inhibited MPT caused by high concentrations of $\mathrm{Ca}^{2+}$ or alloxan- $\mathrm{Ca}^{2+}$. The degree of MPT inhibition by RuR was almost equal to the CsA inhibition (Figure 2). In addition, RuR strongly inhibited the Cyt $c$ release caused by the induc-

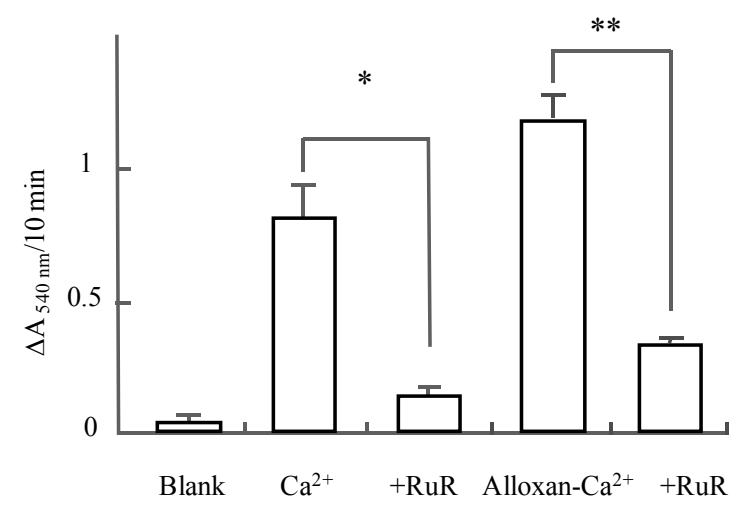

(a)

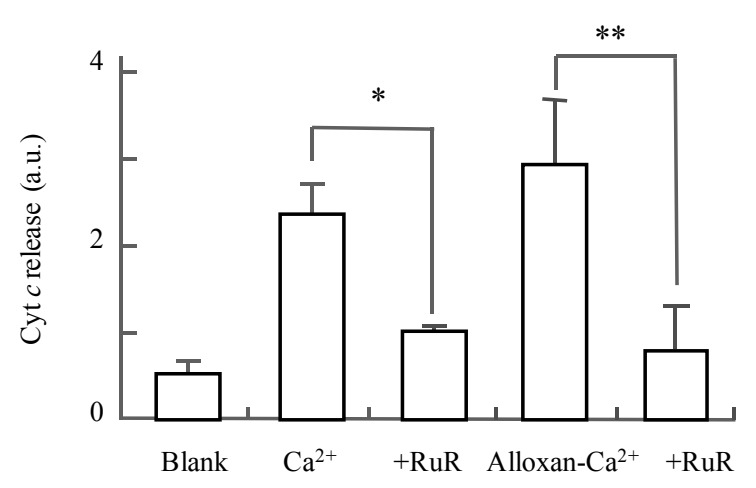

(b)

The incubation medium contained $25 \mathrm{M}$ RuR from the beginning of the experiments. (a) MPT and (b) release of Cyt $c$ were induced by 200 $\mathrm{M} \mathrm{Ca}^{2+}$ or $1 \mathrm{mM}$ alloxan and $20 \mathrm{M} \mathrm{Ca}^{2+}$ in the presence of $5 \mathrm{mM}$ succinate. In blank neither $\mathrm{Ca}^{2+}$, alloxan- $\mathrm{Ca}^{2+}$ nor $\mathrm{RuR}$ was included in the medium. Data are represented as means \pm S.D. of 3 to 11 experiments. * represents $P<0.05$ compared with mitochondria treated with $\mathrm{Ca}^{2+}$ alone. ** represents $P<0.05$ compared with mitochondria treated with alloxan- $\mathrm{Ca}^{2+}$. The other conditions were the same as previously described in Figure 1.

Figure 6. Effects of RuR on MPT and Cyt $c$ release. ers (Figure 6(b)), but CsA did not (Figure 2). These results indicate that RuR significantly inhibits mitochondrial swelling and Cyt $c$ release in mitochondria treated with high concentrations of $\mathrm{Ca}^{2+}$ or alloxan- $\mathrm{Ca}^{2+}$, and these data suggest that VDAC opening may be involved in Cyt $c$ release from mitochondria.

\section{DISCUSSION}

The present study shows that the addition of MPT inducers, such as high concentrations of $\mathrm{Ca}^{2+}$ alone or alloxan- $\mathrm{Ca}^{2+}$, to mitochondrial suspension causes mitochondrial swelling and then Cyt $c$ release from mitochondria isolated from rat livers. The release of Cyt $c$, which is bound to the outer surface of the inner mitochondrial membrane, into the cytosol has an important role in an early event in apoptosis [4,5,7]. CsA, a representative MPT inhibitor, significantly attenuated the extent of MPT induced by $\mathrm{Ca}^{2+}$ alone or alloxan- $\mathrm{Ca}^{2+}$, whereas Cyt $c$ release from mitochondria was still observed (Figure 2 and Table 1).

When the osmotic pressure in the matrix and intermembranous space of mitochondria was equilibrated with PEG that cannot pass the mitochondrial inner membrane, mitochondrial swelling and Cyt $c$ release induced by $\mathrm{Ca}^{2+}$ alone or alloxan- $\mathrm{Ca}^{2+}$ were almost completely prevented (Figure 4). Brustovetsky and Dubinsky demonstrated that high molecular compounds of PEG inhibit mitochondrial swelling induced by high concentrations of $\mathrm{Ca}^{2+}$ but do not inhibit MPT or the collapse of the mitochondrial membrane potential [28]. From these results, we propose that MPT is not required to release Cyt $c$ from mitochondria. $\mathrm{K}^{+}$causes mitochondrial swelling without the induction of MPT in mitochondria isolated from adult rabbit hearts [33]. In our study, the addition of $\mathrm{K}^{+}$to the mitochondrial suspension resulted in the release of Cyt $c$, which was not inhibited by CsA (Figure 5). These results suggest that mitochondrial swelling that is induced through a process other than MPT is involved in the release of Cyt $c$ from mitochondria treated with alloxan- $\mathrm{Ca}^{2+}$ or high concentrations of $\mathrm{Ca}^{2+}$ alone. Halestrap et al. showed that swelling was slightly induced by the addition of $20 \mathrm{mM} \mathrm{KCl} \mathrm{[32].}$ Crouser et al. demonstrated that the swelling and the release of Cyt $c$ were induced at ionic strengths that varied from 5 to $150 \mathrm{mM}$ of $\mathrm{KCl}$ with $0.1 \mathrm{~mol} \mathrm{CaCl}_{2}$, but the activity of an intermembrane space marker adenylate kinase was not released during the swelling at intermediate values of ionic strength [34], suggesting that the rupture of mitochondrial outer membrane might not develop in mitochondria treated with intermediate strength of $\mathrm{KCl}$. Further studies are required to elucidate the mechanism by which Cyt $c$ is released from mitochondria incubated with various ionic strengths of $\mathrm{KCl}$. 
Accumulating evidence indicates that there are mechanisms for passage through the outer mitochondrial membrane including the rupture of the outer membrane or VDAC opening for the release of Cyt $c$ [10,13-17]. Normally, VDAC monomers form an aqueous pore (2.5 to $3 \mathrm{~nm}$ in diameter) that allows uncharged polymers, such as dextran and PEG with a molecular mass of approximately $5 \mathrm{kDa}$, to pass the membranes [35,36]. Cyt $c$ has a molecular mass of $12 \mathrm{kDa}$ and should be unable to pass through the mitochondrial outer membrane by VDAC opening alone. Alternatively, oligomeric forms of VDAC create a large pore, such as the Bax-VDAC pore, with conductance levels 4-fold greater than the levels of VDAC monomers allowing Cyt $c$ translocation across the outer membrane [19,37]. $\mathrm{Ca}^{2+}$ binding site(s) of VDAC is involved in the regulation of VDAC opening [38]. RuR, an inhibitor of MPT and of VDAC opening, strongly inhibited the Cyt $c$ release (Figure 6). RuR binds to $\mathrm{Ca}^{2+}$ binding site(s) of VDAC and completely closes VDAC $[38,39]$. These data suggested that RuR may inhibit the opening of VDAC and oligomerization with MPT induction in mitochondria treated with high concentrations of $\mathrm{Ca}^{2+}$ alone or alloxan- $\mathrm{Ca}^{2+}$. However, another VDAC inhibitor, DIDS [12], did not decrease Cyt $c$ release with high concentrations of $\mathrm{Ca}^{2+}$ (date not shown). G3139 caused a closure of VDAC and increased the sensitivity of MPT induction to high concentrations of $\mathrm{Ca}^{2+}(200 \mathrm{M})$ [40]. Additional studies are needed to elucidate the mechanism by which Cyt $c$ travels through the outer mitochondrial membrane to the cytosol.

Alloxan has cytotoxicity against pancreatic-cells and, thus, causes type 1 (insulin-dependent) diabetes mellitus. Although detailed mechanisms of the cytotoxicity are not yet clearly understood, alloxan causes apoptotic cell death with the release of Cyt $c$ [7]. We previously demonstrated that in mitochondria, which were previously incubated with alloxan, enhanced MPT was clearly observed after addition of succinate [8]. The characteristics of MPT in the present study agreed with our previous report [8]. The inhibitors of mitochondrial function, such as CCCP, STG, and KCN, significantly inhibited MPT but did not inhibit the release of Cyt $c$ (Figure 3(b) and Table 1). These findings suggest that the release of Cyt $c$ from mitochondria is not parallel with MPT induced by alloxan- $\mathrm{Ca}^{2+}$ and may be initiated independently of energy status. The present study demonstrates that mitochondrial swelling directly correlates with Cyt $c$ release from mitochondria treated with high concentrations of $\mathrm{Ca}^{2+}$ alone or alloxan- $\mathrm{Ca}^{2+}$. There are several lines of evidence to support that overexpression of calmodulin in mice results in insulin secretion defects, loss of pancreatic-cells and diabetes [41,42]. The elevation of cytosolic $\mathrm{Ca}^{2+}$ concentrations by free fatty acid induces-cells apoptosis [43]. Several quinones, which have similar structures to alloxan, reduce the threshold of $\mathrm{Ca}^{2+}$ concentrations to induce mitochondrial swelling [26]. These findings lead us to speculate that alloxan may reduce the threshold of $\mathrm{Ca}^{2+}$ concentration to induce MPT accompanied by swelling and that the subsequent mitochondrial dysfunction resulting from Cyt $c$ release may be a cause of pancreatic-cell death.

\section{REFERENCES}

[1] Brookes, P.S., Yoon, Y., Robotham, J.L., Anders, M.W. and Sheu, S.S. (2004) Calcium, ATP, and ROS: A mitochondrial love-hate triangle. American Journal of Physiology. Cell Physiology, 287(4), c817-c833. doi:10.1152/ajpcell.00139.2004

[2] Passarella, S., Atlante, A., Valenti, D. and Bari, L.D. (2003) The role of mitochondrial transport in energy metabolism. Mitochondrion, 2(5), 319-343. doi:10.1016/S1567-7249(03)00008-4

[3] Gunter, T. E., Yule, D. I., Gunter, K. K., Eliseev, R. A. and Salter, J. D., (2004) Calcium and mitochondria. FEBS letters, 567(1), 96-102. doi:10.1016/j.febslet.2004.03.071

[4] Danial, N.N. and Korsmeyer, S.J., (2004) Cell death: Critical control points. Cell, 116(2), 205-219.

[5] Li, P., Nijhawan, D., Budihardjo, I., Srinivasula, S.M., Ahmad, M., Alnemri, E.S. and Wang, X., (1997) Cytochrome $c$ and dATP-dependent formation of Apaf-1/ caspase- 9 complex initiates an apoptotic protease cascade. Cell, 91(4), 479-489.

[6] Sparagna, G.C., Hickson-Bick, D.L., Buja, LM. and McMillin, J.B. (2000) A metabolic role for mitochondria in palmitate-induced cardiac myocyte apoptosis. American Journal of Physiology. Heart and Circulatory Physiology, 279(5), H2124-H2132.

[7] Sakurai, K., Katoh, M., Someno, K. and Fujimoto, Y. (2001) Apoptosis and mitochondrial damage in INS-1 cells treated with alloxan. Biological \& Pharmaceutical Bulletin, 24(8), 876-882. doi: $10.1248 / \mathrm{bpb} .24 .876$

[8] Sakurai, K., Katoh, M. and Fujimoto, Y. (2001) Alloxan-induced mitochondrial permeability transition triggered by calcium, thiol oxidation, and matrix ATP. The Journal of Biological Chemistry, 276(29), 2694226946. doi:10.1074/jbc.M102029200

[9] Kumarswamy, R. and Chandna, S. (2009) Putative partners in Bax mediated cytochrome-c release: ANT, CypD, VDAC or none of them? Mitochondrion, 9(1), 1-8. doi:10.1016/j.mito.2008.10.003

[10] Tsujimoto, Y., Nakagawa, T. and Shimizu, S. (2006) Mitochondrial membrane permeability transition and cell death. Biochimica et Biophysica Acta, 1757(9-10), 12971300 .

doi:10.1016/j.bbabio.2006.03.017

[11] Ott, M., Robertson, J.D., Gogvadze, V., Zhivotovsky, B. and Orrenius, S. (2002) Cytochrome c release from mitochondria proceeds by a two-step process. Proceedings of the National Academy of Sciences of the United States 
of America, 99(3), 1259-1263.

doi:10.1073/pnas.241655498

[12] Petrosillo, G., Ruggiero, F.M. and Paradies, G. (2003) Role of reactive oxygen species and cardiolipin in the release of cytochrome c from mitochondria. The FASEB Journal, 17(15), 2202-2208. doi:10.1096/fj.03-0012com

[13] Tsujimoto, Y. and Shimizu, S. (2000) VDAC regulation by the Bcl-2 family of proteins. Cell Death and Differentiation, 7(12), 1174-1181. doi:10.1038/sj.cdd.4400780

[14] Garrido, C., Galluzzi, L., Brunet, M., Puig, P. E., Didelot, C. and Kroemer, G. (2006) Mechanisms of cytochrome $c$ release from mitochondria. Cell Death and Differentiation, 13(9), 1423-1433. doi:10.1038/sj.cdd.4401950

[15] Brustovetsky, N., Brustovetsky, T., Jemmerson, R. and Dubinsky, J.M. (2002) Calcium-induced cytochrome $c$ release from CNS mitochondria is associated with the permeability transition and rupture of the outer membrane. Journal of Neurochemistry, 80(2), 207-218. doi:10.1046/j.0022-3042.2001.00671.x

[16] Petit, P.X., Goubern, M., Diolez, P., Susin, S.A., Zamzami, N. and Kroemer, G. (1998) Disruption of the outer mitochondrial membrane as a result of large amplitude swelling: the impact of irreversible permeability transition. The FASEB Journal, 426(1), 111-116.

[17] Doran, E. and Halestrap, A.P. (2000) Cytochrome $c$ release from isolated rat liver mitochondria can occur independently of outer-membrane rupture: Possible role of contact sites. The Biochemical Journal, 348(2), 343-350. doi:10.1042/0264-6021:3480343

[18] Jürgensmeier, J.M., Xie, Z., Deveraux, Q., Ellerby, L., Bredesen, D. and Reed, J.C. (1998) Bax directly induces release of cytochrome $c$ from isolated mitochondria. Proceedings of the National Academy of Sciences of the United States of America, 95(9), 4997-5002. doi:10.1073/pnas.95.9.4997

[19] Shimizu, S., Ide, T., Yanagida, T. and Tsujimoto, Y. (2000) Electrophysiological study of a novel large pore formed by Bax and the voltage-dependent anion channel that is permeable to cytochrome $c$. The Journal of Biological Chemistry, 275(16), 12321-12325. doi:10.1074/jbc.275.16.12321

[20] Kim, T.H., Zhao, Y., Barber, M.J., Kuharsky, D.K. and Yin, X.M. (2000) Bid-induced cytochrome $c$ release is mediated by a pathway independent of mitochondrial permeability transition pore and Bax. The Journal of Biological Chemistry, 275(50), 39474-39481. doi:10.1074/jbc.M003370200

[21] Uren, R.T., Dewson, G., Bonzon, C., Lithgow, T., Newmeyer, D.D. and Kluck, R.M. (2005) Mitochondrial release of pro-apoptotic proteins: electrostatic interactions can hold cytochrome c but not Smac/DIABLO to mitochondrial membranes. The Journal of Biological Chemistry, 280(3), 2266-2274. doi:10.1074/jbc.M411106200

[22] Haworth, R.A. and Hunter, D.R. (1979) The $\mathrm{Ca}^{2+}$-induced membrane transition in mitochondria. II. Nature of the $\mathrm{Ca}^{2+}$ trigger site. Archives of Biochemistry and Biophysics, 195(2), 460-467. doi:10.1016/0003-9861(79)90372-2
[23] Johnston, J.D. and Brand, M.D. (1990) The mechanism of $\mathrm{Ca}^{2+}$ stimulation of citrulline and $N$-acetylglutamate synthesis by mitochondria. Biochimica et Biophysica Acta, 1033(1), 85-90.

[24] Paola, M.D. and Lorusso, M. (2006) Interaction of free fatty acids with mitochondria: Coupling, uncoupling and permeability transition. Biochimica et Biophysica Acta, 1757(9-10), 1330-1337. doi:10.1016/j.bbabio.2006.03.024

[25] Mironova, G.D., Gritsenko, E., Gateau-Roesch, O., Levrat, C., Agafonov, A., Belosludtsev, K., Prigent, A. F., Muntean, D., Dubois, M. and Ovize, M. (2004) Formation of palmitic acid $/ \mathrm{Ca}^{2+}$ complexes in the mitochondrial membrane: a possible role in the cyclosporin-insensitive permeability transition. Journal of Bioenergetics and Biomembranes, 36(2), 171-178. doi:10.1023/B:JOBB.0000023620.42653.b7

[26] Halestrap, A.P., Woodfield, K.Y. and Connern, C.P. (1997) Oxidative stress, thiol reagents, and membrane potential modulate the mitochondrial permeability transition by affecting nucleotide binding to the adenine nucleotide translocase. The Journal of Biological Chemistry, 272(6), 3346-3354. doi:10.1074/jbc. 272.6 .3346

[27] Andreu, G.L.P., Delgado, R., Velho, J.A., Curti, C. and Vercesi, A.E. (2005) Mangiferin, a natural occurring glucosyl xanthone, increases susceptibility of rat liver mitochondria to calcium-induced permeability transition. Archives of Biochemistry and Biophysics, 439(2), 184-193. doi:10.1016/j.abb.2005.05.015

[28] Brustovetsky, N. and Dubinsky, J.M. (2000) Limitations of cyclosporin A inhibition of the permeability transition in CNS mitochondria. The Journal of Neuroscience, 20(22), 8229-8237.

[29] Gunter, T.E., Buntinas, L., Sparagna, G.C. and Gunter, K.K. (1998) The $\mathrm{Ca}^{2+}$ transport mechanisms of mitochondria and $\mathrm{Ca}^{2+}$ uptake from physiological-type $\mathrm{Ca}^{2+}$ transients. Biochimica et Biophysica Acta, 1366(1-2), 5-15. doi:10.1016/S0005-2728(98)00117-0

[30] Armstrong, J.S., Yang, H., Duan, W. and Whiteman, M. (2004) Cytochrome bc(1) regulates the mitochondrial permeability transition by two distinct pathways. The Journal of Biological Chemistry, 279(48), 50420-50428. doi:10.1074/jbc.M408882200

[31] Sakurai, K., Stoyanovsky, D.A., Fujimoto, Y. and Cederbaum, A.I. (2000) Mitochondrial permeability transition induced by 1 -hydroxyethyl radical. Free Radical Biology \& Medicine, 28(2), 273-280. doi:10.1016/S0891-5849(99)00236-1

[32] Halestrap, A.P., Quinlan, P.T., Whipps, D.E. and Armston, A.E. (1986) Regulation of the mitochondrial matrix volume in vivo and in vitro. The role of calcium. The Biochemical Journal, 236(3), 779-787.

[33] Korge, P., Honda, H.M. and Weiss, J.N. (2005) $\mathrm{K}^{+}$-dependent regulation of matrix volume improves mitochondrial function under conditions mimicking ischemia-reperfusion. American Journal of Physiology. Heart and Circulatory Physiology, 289(1), H66-H77. doi:10.1152/ajpheart.01296.2004

[34] Crouser, E.D., Gadd, M.E., Julian, M.W., Huff, J.E., Broekemeier, K.M., Robbins, K.A. and Pfeiffer, D.R. 
(2003) Quantitation of cytochrome $c$ release from rat liver mitochondria. Analytical Biochemistry, 317(1), 67-75. doi:10.1016/S0003-2697(03)00044-7

[35] Colombini, M. (1980) Structure and mode of action of a voltage dependent anion-selective channel (VDAC) located in the outer mitochondrial membrane. Annals of the New York Academy of Sciences, 341, 552-63. doi:10.1111/j.1749-6632.1980.tb47198.x

[36] Zalman, L.S., Nikaido, H. and Kagawa, Y. (1980) Mitochondrial outer membrane contains a protein producing nonspecific diffusion channels. The Journal of Biological Chemistry. 255(5), 1771-1774.

[37] Shoshan-Barmatz, V., Israelson, A., Brdiczka, D. and Sheu, S.S. (2006) The voltage-dependent anion channel (VDAC): Function in intracellular signalling, cell life and cell death. Current Pharmaceutical Design, 12(18), 2249-2270. doi: $10.2174 / 138161206777585111$

[38] Gincel, D., Zaid, H. and Shoshan-Barmatz, V. (2001) Calcium binding and translocation by the voltage-dependent anion channel: A possible regulatory mechanism in mitochondrial function. The Biochemical Journal, 358(Pt1), 147-155. doi:10.1042/0264-6021:3580147

[39] Israelson, A., Abu-Hamad, S., Zaid, H., Nahon, E. and
Shoshan-Barmatz, V. (2007) Localization of the voltagedependent anion channel-1 $\mathrm{Ca}^{2+}$-binding sites. Cell Calcium, 41(3), 235-244.

doi:10.1016/i.ceca.2006.06.005

[40] Tikunov, A., Johnson, C.B., Pediaditakis, P., Markevich, N., Macdonald, J.M., Lemasters, J.J. and Holmuhamedov, E. (2010) Closure of VDAC causes oxidative stress and accelerates the $\mathrm{Ca}(2+)$-induced mitochondrial permeability transition in rat liver mitochondria. Archives of Biochemistry and Biophysics, 495(2), 174-181. doi:10.1016/j.abb.2010.01.008

[41] Gómez Dumm, C.L., Atwater, I., Epstein, P.N. and Gagliardino, J.J. (1994) Quantitative immunocytochemical study of islet cell populations in diabetic calmodulintransgenic mice. Virchows Archiv, 425(1), 73-77.

[42] Epstein, P.N., Ribar, T.J., Decker, G.L., Yaney, G. and Means, A.R. (1992) Elevated beta-cell calmodulin produces a unique insulin secretory defect in transgenic mice. Endocrinology, 130(3), 1387-1393. doi:10.1210/en.130.3.1387

[43] Gwiazda, K.S., Yang, T.L., Lin, Y. and Johnson, J.D. (2009) Effects of palmitate on ER and cytosolic $\mathrm{Ca}^{2+}$ homeostasis in beta-cells. American Journal of Physiology. Endocrinology and Metabolism, 296(4), E690-E701. doi:10.1152/ajpendo.90525.2008 